\title{
A prospective trial of vaccine to prevent hepatitis B virus reactivation after hematopoietic stem cell transplantation
}

\author{
Koji Nishikawa ${ }^{1} \cdot$ Kiminori Kimura $\mathbb{D}^{1} \cdot$ Yoshinobu Kanda ${ }^{2} \cdot$ Masaya Sugiyama $^{3} \cdot$ Kazuhiko Kakihana $\mathbb{D}^{4} \cdot$

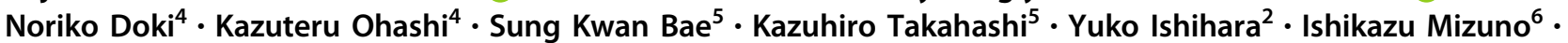 \\ Yasushi Onishi ${ }^{7} \cdot$ Masahiro Onozawa $^{8} \cdot$ Makoto Onizuka $^{9} \cdot$ Masahide Yamamoto $^{10} \cdot$ Tetsuya Ishikawa $^{11}$. \\ Kazuaki Inoue $^{12}$. Shigeru Kusumoto ${ }^{13} \cdot$ Satoshi Hashino $^{8} \cdot$ Hidetsugu Saito $^{14} \cdot$ Tatsuya Kanto $^{15} \cdot$ Hisashi Sakamaki $^{4}$. \\ Masashi Mizokami ${ }^{3}$
}

Received: 5 October 2019 / Revised: 3 February 2020 / Accepted: 5 February 2020 / Published online: 18 February 2020

(c) The Author(s) 2020. This article is published with open access

\begin{abstract}
Hepatitis B virus (HBV) reactivation reportedly occurs frequently after hematopoietic stem cell transplantation (HSCT) in resolved HBV-infected patients. Here, 50 patients with resolved HBV infections and scheduled to undergo HSCT were enrolled; all subjects were vaccinated with three doses of hepatitis B vaccine 12 months after HSCT and the incidence of HBV reactivation was monitored. The patients' characteristics were: median age, 61 (34-72) years; male/female, 27/19; allogeneic/autologous, 40/6; bone marrow/peripheral blood stem cells/cord blood, 26/16/4. Of the 46 patients who underwent HSCT, 19 were excluded and did not make it to vaccination due to relapse of underlying disease, HBV reactivation within 12 months of HSCT, or transfer of patients. The remaining 27 were vaccinated 12 months after HSCT and monitored for 2 years. Six showed HBV reactivation, with a 2-year cumulative reactivation incidence of $22.2 \%$; the same incidence was $27.3 \%$ only in allogeneic HSCT patients. Factors associated with HBV reactivation included the discontinuation of immunosuppressants $(P=0.0379)$ and baseline titers of antibody against hepatitis B surface antigen $(P=$ 0.004). HBV reactivation with vaccination following HSCT could occur despite maintenance of serum anti-HBs at more than protective levels.
\end{abstract}

Supplementary information The online version of this article (https:// doi.org/10.1038/s41409-020-0833-5) contains supplementary material, which is available to authorized users.

Kiminori Kimura

kkimura@ cick.jp

1 Division of Hepatology, Tokyo Metropolitan Cancer and Infectious Diseases Center, Komagome Hospital, Tokyo, Japan

2 Division of Hematology, Jichi Medical University, Shimotuke, Japan

3 Genome Medical Science Project, National Center for Global Health and Medicine, Ichikawa, Japan

4 Division of Hematology, Tokyo Metropolitan Cancer and Infectious Diseases Center, Komagome Hospital, Tokyo, Japan

5 The Center for Liver Disease, Hamanomachi Hospital, Fukuoka, Japan

6 Department of Hematology, Hyogo Cancer Center, Akashi, Japan

7 Department of Hematology and Rheumatology, Tohoku University Hospital, Sendai, Japan
8 Department of Hematology, Hokkaido University Hospital, Sapporo, Japan

9 Department of Hematology and Oncology, Tokai University School of Medicine, Isehara, Japan

10 Department of Hematology, Tokyo Medical and Dental University, Tokyo, Japan

11 Department of Radiological and Medical Laboratory Sciences, Nagoya University Graduate School of Medicine, Nagoya, Japan

12 Department of Gastroenterology, Showa University Fujigaoka Hospital, Yokohama, Japan

13 Department of Hematology and Oncology, Nagoya City University Graduate School of Medical Sciences, Nagoya, Japan

14 Division of Pharmacotherapeutics, Keio University Faculty of Pharmacy, Tokyo, Japan

15 The Research Center for Hepatitis and Immunology, National Center for Global Health and Medicine, Ichikawa, Japan 


\section{Introduction}

Hepatitis B virus (HBV) reactivation following anticancer drugs, immunosuppressants, or other chemotherapies is a major clinical problem, irrespective of past infection. HBV reactivation is observed in patients negative for hepatitis $\mathrm{B}$ surface antigen (HBsAg) (serum HBV-DNA-negative) and positive for anti-hepatitis $B$ core antigen $(\mathrm{HBc})$ and antihepatitis B surface antibodies (anti-HBs) [1]. HBV reactivation is most commonly reported in patients following hematopoietic stem cell transplantation (HSCT) [2-5]. Chronic graft-versus-host disease (GVHD) [2, 6], corticosteroid exposure [2], and loss of anti-HBs [7] are also hypothesized to cause HBV reactivation. In addition, HBV reactivation may result in the discontinuation of effective therapies for hematological diseases, worsening the patient's prognosis [8]. Current guidelines recommend that HBsAg-negative, anti-HBc-positive patients with undetectable serum HBV-DNA and regardless of anti-HBs status who receive chemotherapy and/or immunosuppression should be followed carefully by alanine aminotransferase (ALT) and HBV-DNA testing and treated with nucleoside/ nucleotide analogs (NA) upon confirmation of HBV reactivation before ALT elevation $[9,10]$. The frequency of monitoring can range from 1 to 3 months depending on the type of immunosuppressive therapy and comorbidities. NA prophylaxis is recommended for anti-HBc-positive patients receiving bone marrow or stem cell transplantation [5], although the optimal duration of prophylaxis is not known.

The incidence of HBV reactivation after HSCT in HBVresolved patients is $\sim 40 \%$ [11], suggesting that more than half of HSCT patients do not require NA prophylactic administration. Thus, NA prophylaxis seems to be economically questionable. Furthermore, unlike chemotherapy and immunosuppressant administration, the onset of HBV reactivation after HSCT has not been determined, although it has been reported 5 years following HSCT [12]. Such long onset times require long-term preventive NA administration. Considering this, we focused on HB vaccination as an inexpensive and safe alternative, but potentially effective, preventive treatment. We investigated the preventive effect of vaccination, because low anti-HBs titer is associated with reactivation $[11,13]$. The European Conference on Infections in Leukaemia recommend that patients infected with HBV before HSCT (HBsAg-negative and anti-HBc-positive) should be assessed regularly for anti-HBs titers and vaccinated if they have unprotective titers; if anti-HBs titers are $<10 \mathrm{mIU} / \mathrm{mL}$ at $1-2$ months after initial three vaccine doses, an additional series of three doses should be considered [14]. However, to the best of our knowledge, no clinical studies have examined the preventive effect of vaccine on reactivation in patients with resolved HBV infection after HSCT. In this study, we investigated the efficacy of $\mathrm{HB}$ vaccine in preventing reactivation in resolved $\mathrm{HBV}$-infected patients after HSCT.

\section{Methods}

\section{Study design and patients}

In this multicenter, prospective clinical trial, we sequentially enrolled patients with a past HBV infection, defined as HBsAg-negative and anti-HBc-positive, and scheduled to undergo HSCT between August 1, 2013 and January 31, 2016 at the Komagome Hospital enrollment center. All patients were vaccinated 12 months after HSCT (see Supplementary Materials). The baseline HBV status at enrollment was determined based on serological results for anti-HBs using an anti-HBs kit and a fully automated chemiluminescent enzyme immunoassay system (Architect i2000SR analyzer; Abbott Japan, Tokyo, Japan). Serologic $\mathrm{HBsAg}$ and anti-HBc were measured by chemiluminescent enzyme immunoassay (Fuji Rebio, Tokyo, Japan). Serum HBV-DNA titers were measured using the COBAS TaqMan HBV test kit (Roche, Branchburg, NJ, USA) with a low detection limit of $1.3 \log \mathrm{IU} / \mathrm{mL}$.

The review board of each participating institution approved the protocol and all patients provided written informed consent. Eligible participants were between 18 and 75 years of age, scheduled to undergo first HSCT, and were HBsAg-negative and anti-HBc-positive. We excluded patients with human immunodeficiency virus or hepatitis $C$ virus infection. We also excluded patients with a history of past hypersensitivity to vaccination. All eligible patients were vaccinated. The complete eligibility criteria are included in the Supplementary appendix. This study is registered with UMIN (no. UMIN000011543).

\section{Procedure}

HBV-DNA was quantified before HSCT to confirm the patient's serum as HBV-DNA-negative. Enrolled patients were prospectively monitored by performing the HBVDNA assay once per month for 1 year after HSCT, and then once every 2 months until 3 years after HSCT. Serum HBsAg and anti-HBs was also monitored once every 2 months. HBV vaccination was commenced 12 months after HSCT, with additional doses administered at 13 and 18 months after HSCT. According to the 2013 IDSA Clinical Practice Guideline [15], three doses of HB vaccine should be administered 6-12 months after HSCT. We postulated that vaccine-induced antibody production was likely to decrease by immunosuppressive treatments; thus, we chose to vaccinate 12 months after HSCT, when chronic GVHD is expected to converge. 


\section{Definition of response to vaccination}

Patients were vaccinated with three doses $(10 \mu \mathrm{g})$ of a recombinant absorbed HBV vaccine (Bimmugen, Kaketsuken, Kumamoto, Japan). Additional inoculations were continued even if anti-HBs titers were elevated after the initial vaccination. Vaccination was performed for both allogeneic and autologous HSCT cases. Vaccine responders were defined as patients in whom (1) anti-HBs titer increased from $\leq 10 \mathrm{mIU} / \mathrm{mL}$ before vaccination to $\geq 10 \mathrm{mIU} / \mathrm{mL}$ after vaccination, or (2) anti-HBs titer was $\geq 10 \mathrm{mIU} / \mathrm{mL}$ before vaccination, but increased in two consecutive assays after vaccination.

\section{Definition of HBV reactivation}

We defined HBV reactivation as conversion from HBVDNA-negative to HBV-DNA-positive after HSCT, with an HBV-DNA assay threshold of $\geq 1.3 \log \mathrm{IU} / \mathrm{mL}$. When HBV reactivation was observed, therapeutic intervention for chronic hepatitis B (entecavir, $0.5 \mathrm{mg} /$ day) was strongly recommended. In cases of relapse or refractory disease of the primary disease and if a subject was indicated for a second HSCT, the patient was excluded and monitoring was discontinued.

\section{Safety}

Adverse events and reactions observed during the study were evaluated and named using the Common Terminology Criteria for Adverse Events v4.0 Japanese translation, and graded 1-5. Here, deterioration by one or more grades according to the criteria was deemed to be an adverse event. The same criteria were applied for abnormal laboratory values. Acute or chronic GVHD were diagnosed according to the National Institutes of Health consensus guidelines.

\section{Amino acid sequence of $\mathrm{HBs}$}

Serum samples were stored at $-80{ }^{\circ} \mathrm{C}$ until assayed. DNA was extracted from $200 \mu \mathrm{L}$ of serum using the QIAamp DNA Blood Mini Kit (Qiagen, Valencia, CA, USA) according to the manufacturer's instructions, and used for PCR amplification and direct sequencing of the HBV S gene, as previously reported [16, 17]. The sequencing products were analyzed using an ABI 3130xl DNA analyzer (Applied Biosystems). The sequences were aligned using the GenBank sequences corresponding to HBV genotypes.

\section{Outcomes}

The primary endpoint was incidence of HBV reactivation in HSCT recipients immunized with $\mathrm{HB}$ vaccine. The secondary endpoints were liver toxicity and frequency of fulminant hepatitis caused by HBV reactivation, and safety of HB vaccination. Post hoc exploratory outcomes included HBs escape mutant analysis by sequencing HBsAg using serum of patients showing reactivation after vaccination.

\section{Statistical analyses}

Categorical variables are presented as number (percentage) and continuous variables as median (range). Chi-square or Fisher's exact tests were used to compare differences between categorical variables. Continuous variables were compared using the Mann-Whitney U test. The cumulative incidence of HBV reactivation was estimated by competing risks model, and risk factors associated with HBV reactivation after vaccination were evaluated using the Fine and Gray model for univariate analysis. We defined censor for any reasons as competing risk. $P$ values $<0.05$ were considered to be statistically significant. All analyses were performed using R version 3.6.1 (R Foundation for Statistical Computing, Vienna, Austria).

\section{Results}

\section{Characteristics of the patients}

We enrolled 50 patients who were $\mathrm{HBsAg}$-negative and antiHBc-positive under HSCT schedule from 11 hospitals in Japan. We observed 46 patients; the other four patients died due to deterioration caused by an underlying disease after HSCT. Patients' characteristics are summarized in Table 1. The median age was 61 (range 34-72) years, with 27 males (58.7\%). Stem cell source was bone marrow for 26 patients (56.5\%), peripheral blood stem cells for 16 patients (34.8\%), and cord blood (CB) for 4 patients $(8.7 \%)$. Acute and chronic GVHD occurred in $29(63 \%)$ and $22(47.8 \%)$ patients, respectively. The immunosuppressants used were corticosteroids for $30(65.2 \%)$, cyclosporine for $11(23.9 \%)$, and tacrolimus for 31 (67.4\%) patients. During the 12 months of follow-up after HSCT, seven patients died of relapse of an underlying disease, two patients were excluded from further observation due to progression of primary disease, and three patients were transferred to other hospitals; thus, in total, 12 patients were excluded. Seven HBV reactivation events (15.2\%) were detected during this period (Fig. 1).

\section{Incidence of $\mathrm{HBV}$ reactivation after vaccination}

Excluding the above patients, 27 patients $(58.7 \%)$ received the first dose of the HB vaccine 12 months after HSCT, with additional doses at 13 and 18 months post-HSCT. These vaccinated patients were observed for 2 years. There were 
Table 1 Patients characteristics, $(n=46)$.

\begin{tabular}{lc}
\hline Characteristics & $n=46$ \\
\hline Age (years), median & $61(34-72)$ \\
Male, $n(\%)$ & $27(58.7 \%)$ \\
Primary disease, $n(\%)$ & \\
AML & $16(34.8 \%)$ \\
ALL & $4(8.7 \%)$ \\
CML & $2(4.3 \%)$ \\
MDS & $13(28.2 \%)$ \\
MM & $4(8.7 \%)$ \\
NHL & $7(15.2 \%)$ \\
Stem cell source, $n(\%)$ & \\
Bone marrow & $26(56.5 \%)$ \\
PBSC & $16(34.8 \%)$ \\
Autologous/allogeneic & $6(13 \%) / 10(21.7 \%)$ \\
Cord blood & $4(8.7 \%)$ \\
Conditioning therapy, $n(\%)$ & \\
MAC/RIC & $23(50 \%) / 23(50 \%)$ \\
HLA match, $n(\%)$ & $25(54.3 \%)$ \\
Immunosuppressant, $n(\%)$ & \\
Corticosteroid & $30(65.2 \%)$ \\
Cyclosporine & $11(23.9 \%)$ \\
Tacrolimus & $31(67.4 \%)$ \\
Mycophenolate mofetil & $6(13 \%)$ \\
Short methotrexate & $34(73.9 \%)$ \\
Anti-HBs at baseline, median & $100.9(<2.5-1000<)$ \\
Anti-HBc at baseline, median & $17.1(1.2-124)$ \\
GVHD, $n$ (\%) & \\
Acute GVHD & $29(63 \%)$ \\
Chronic GVHD & $22(47.8 \%)$ \\
\hline &
\end{tabular}

no patients in whom vaccine administration was discontinued due to serious adverse events after vaccination. After vaccination, HBV reactivation occurred in six patients, and the 2-year cumulative incidence of $\mathrm{HBV}$ reactivation was $22.2 \%$ (Fig. 2a). In case of allogeneic HSCT patients, the 2-year cumulative incidence of $\mathrm{HBV}$ reactivation was $27.3 \%$ (Fig. 2b). Corticosteroids were used in all HBV-reactivated patients for immunosuppression (Table 2).

The background of patients with HBV reactivation is summarized in Table 3. Reactivation-associated hepatitis did not occur, and no patients showed liver failure owing to entecavir therapy (Table 4). Although Patient 13 showed elevated serum ALT levels, this was due to drug-induced liver damage by voriconazole, and not by HBV reactivation. Within 12 months after HSCT, seven patients (15.2\%) had detectable $\mathrm{HBV}$ reactivation, consistent with the high rates of reactivation after HSCT described previously [3].

\section{Factors associated with reactivation}

The discontinuation of immunosuppressants and anti-HBs titers at baseline was identified to be most closely associated with the cumulative incidence of $\mathrm{HBV}$ reactivation
(Fig. 3a-d). Interestingly, chronic GVHD related to the use of immunosuppressants did not contribute significantly to the incidence of $\mathrm{HBV}$ reactivation. Furthermore, anti-HBs titers at the time of vaccination were not correlated with $\mathrm{HBV}$ reactivation, unlike baseline titers.

\section{Response to HBV vaccine}

As shown in Fig. 4, no significant difference was found in the incidence of $\mathrm{HBV}$ reactivation between the vaccine responder and nonresponder groups. Among the 21 patients whose infections did not reactivate, 16 (76.2\%) had antiHBs titers of $10 \mathrm{mIU} / \mathrm{mL}$ or more. In contrast, five patients $(23.8 \%)$ did not show reactivated infection, despite antiHBs titers of $<10 \mathrm{mIU} / \mathrm{mL}$. However, we found high levels of serum anti-HBs $(>10 \mathrm{mIU} / \mathrm{mL})$ in four $(66.7 \%)$ of six patients with $\mathrm{HBV}$ reactivation, suggesting escape mutants of HBsAg. To test this hypothesis, HBsAg sequencing was performed using sera from all HBV-reactivated patients.

\section{Amino acid sequence of $\mathrm{HBsAg}$ and clinical course of patients with $\mathrm{HBV}$ reactivation following $\mathrm{HB}$ vaccination}

Sequencing of the HBsAg gene in the HBV-reactivated patients' sera was successful in only three (patients 13, 23, and 42) out of six cases (Table 3), because HBV-DNA levels were very low in the sera of the remaining three cases. In addition, whenever HBV reactivation was confirmed, entecavir treatment was immediately initiated, reducing viremia and making $\mathrm{HBsAg}$ sequencing impossible in the remaining three cases. The three tested patients presented HBsAg mutations that included sL110I, sK122R, sD144E, and sR160K, and sV177A only in one case (patient 23) (Fig. 5). Among these mutations, the sD144E substitution, which resides in a major hydrophilic region of S-HBsAg [18, 19], is known to hamper S-HBsAg recognition by antibodies. Thus, we observed only one HBV reactivation that could be attributed to $\mathrm{HBsAg}$ escape mutation.

\section{Discussion}

In our study, the 2-year cumulative incidence of reactivation was $22.2 \%$ after vaccine administration, and $28.9 \%$ in 3 years after HSCT despite vaccine intervention. This suggests that $\mathrm{HB}$ vaccination cannot prevent $\mathrm{HBV}$ reactivation completely; this is in contrast to a previous study reporting preventive effects of vaccination retrospectively [20]. Seto et al., in a prospective study, reported an HBV reactivation incidence of $\sim 40 \%, 2$ years after HSCT [11]. Although further randomized studies are needed, the effectiveness of 
Fig. 1 Flow diagram of participants. Trial flow chart.

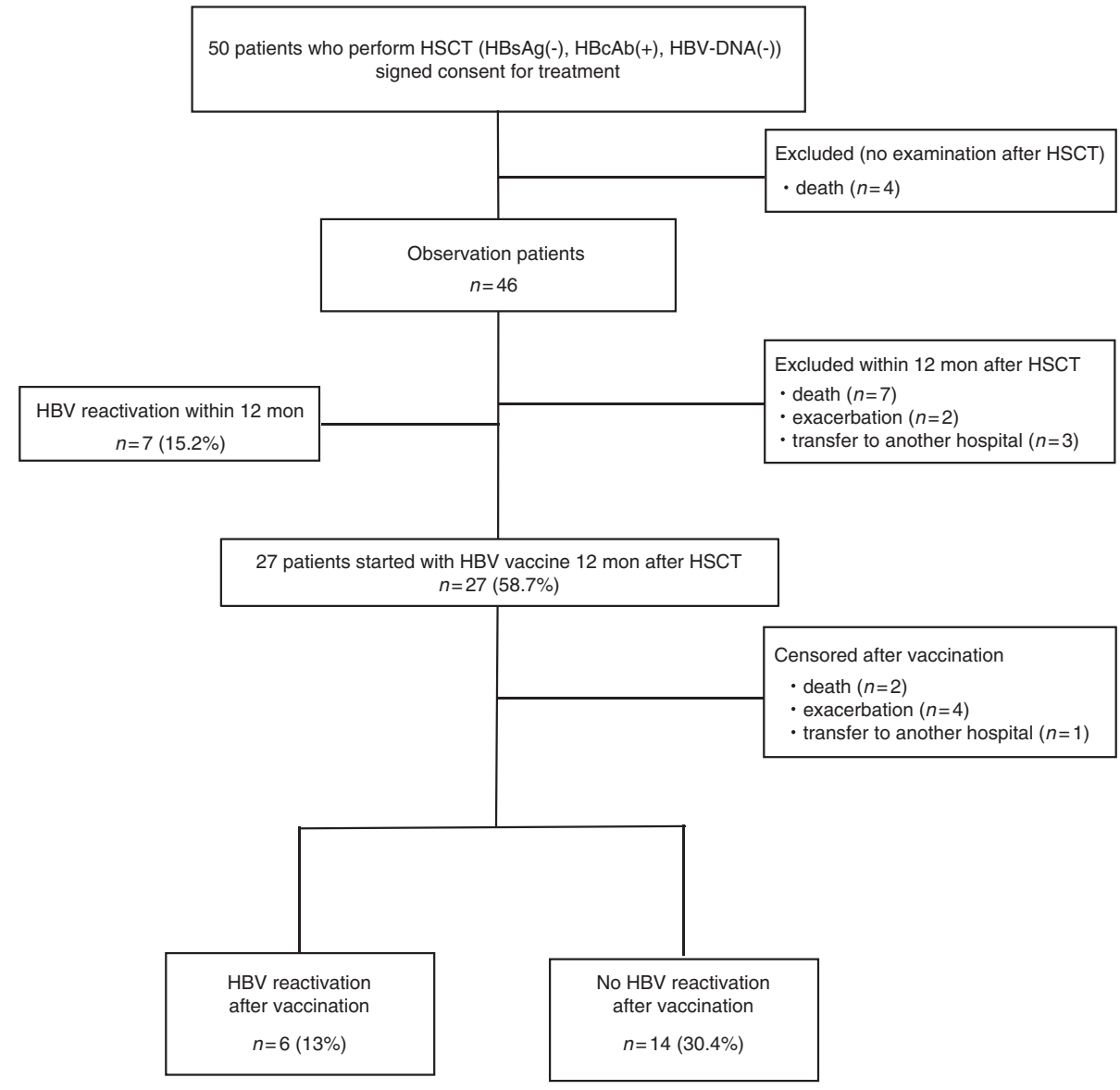

HBV reactivation after

vaccination. Cumulative incidence of $\mathrm{HBV}$ reactivation after vaccination for (a) all HSCT patients and (b) allogeneic HSCT patients. The cumulative incidence of HBV reactivation was estimated by competing risks model. We defined censor for any reasons as competing risk. $P$ values $<0.05$ were considered to be statistically significant. a

All HSCT

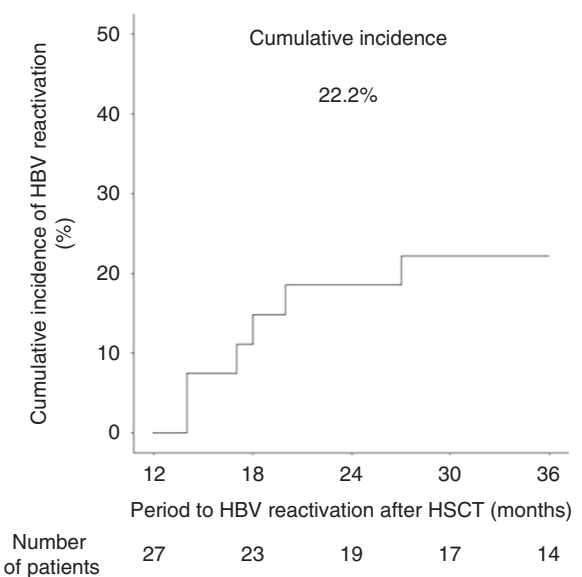

b

Allogeneic HSCT

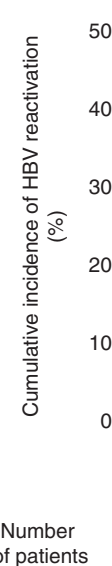

Cumulative incidence

$$
27.3 \%
$$

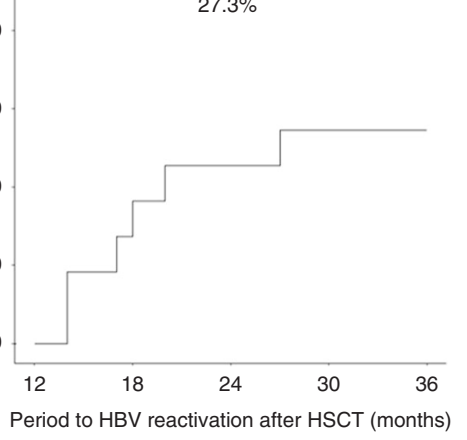

$\begin{array}{lllll}22 & 18 & 15 & 13 & 11\end{array}$ vaccination is currently questionable. Generally, waiting 6-12 months after HSCT is not considered a major risk for HBs-seronegative patients before HSCT administration [21]. Reportedly, HB vaccination can be administered from 6 to 12 months following HSCT, but early posttransplant vaccination can be considered for anti-HBs-positive patients before HSCT [21]. Although we chose vaccination time at 12 months after HSCT, others have reported that higher titers of anti-HBs produce higher reactivity to the vaccine $[20,22]$; therefore, one should consider vaccine administration at 6 months following HSCT.

Anti-HBs titers are negatively correlated with HBV reactivation as reported in some retrospective studies $[1,3,23]$. Therefore, we vaccinated our subjects to elevate anti-HBs titers. However, four patients, in whom reactivation occurred despite high anti-HBs titers $(>10 \mathrm{mIU} / \mathrm{mL})$, 
Table 2 Patients characteristics following $\mathrm{HB}$ vaccine.

\begin{tabular}{|c|c|c|c|c|}
\hline Characteristics & ALL $n=27$ & $\begin{array}{l}\text { HBV reactivation } \\
n=6\end{array}$ & $\begin{array}{l}\text { No } \mathrm{HBV} \text { reactivation } \\
n=21\end{array}$ & $P$ \\
\hline Age (years), median & $60(34-72)$ & $59.5(34-72)$ & $60(50-68)$ & 0.9665 \\
\hline Male, $n(\%)$ & $15(55.6 \%)$ & $5(83.3 \%)$ & $10(47.6 \%)$ & 0.1819 \\
\hline \multicolumn{5}{|l|}{ Primary disease, $n(\%)$} \\
\hline AML & $7(25.9 \%)$ & $2(33.3 \%)$ & $5(23.8 \%)$ & \\
\hline ALL & $4(14.8 \%)$ & $1(16.7 \%)$ & $3(14.3 \%)$ & \\
\hline CML & $1(3.7 \%)$ & $1(16.7 \%)$ & 0 & \\
\hline MDS & $6(22.2 \%)$ & 0 & $6(28.6 \%)$ & \\
\hline MM & $4(14.8 \%)$ & 0 & $4(19 \%)$ & \\
\hline NHL & $5(18.5 \%)$ & $2(33.3 \%)$ & $3(14.3 \%)$ & \\
\hline \multicolumn{5}{|l|}{ Stem cell source, $n(\%)$} \\
\hline Bone marrow & $15(55.6 \%)$ & $5(83.3 \%)$ & $10(47.6 \%)$ & 0.1819 \\
\hline Autologous PBSC & $5(18.5 \%)$ & 0 & $5(23.8 \%)$ & \\
\hline Allogeneic PBSC & $6(22.2 \%)$ & $1(16.7 \%)$ & $5(23.8 \%)$ & \\
\hline Cord blood & $1(3.7 \%)$ & 0 & $1(4.8 \%)$ & \\
\hline \multicolumn{5}{|l|}{ Conditioning therapy, $n(\%)$} \\
\hline MAC/RIC & $16(59.2 \%) / 11(40.7 \%)$ & \%) $2(33.3 \%) / 4(66.7 \%$ & \%) $14(66.7 \%) / 7(33.3 \%)$ & 0.1874 \\
\hline HLA match, $n(\%)$ & $17(63 \%)$ & $4(66.7 \%)$ & $13(61.9 \%)$ & 0.9999 \\
\hline Acute GVHD, $n(\%)$ & $13(48.1 \%)$ & $2(33.3 \%)$ & $11(52.3 \%)$ & 0.6483 \\
\hline Chronic GVHD, $n(\%)$ & $16(59.2 \%)$ & $5(83.3 \%)$ & $11(52.3 \%)$ & 0.3497 \\
\hline \multicolumn{5}{|l|}{ Immunosuppressant, $n(\%)$} \\
\hline Corticosteroid & $18(66.7 \%)$ & $6(100 \%)$ & $12(57.1 \%)$ & 0.0707 \\
\hline Cyclosporine & $5(18.5 \%)$ & $1(16.7 \%)$ & $4(19 \%)$ & \\
\hline Tacrolimus & $18(66.7 \%)$ & $5(83.3 \%)$ & $13(61.9 \%)$ & \\
\hline Mycophenolate mofetil & $3(11.1 \%)$ & $1(16.7 \%)$ & $2(9.5 \%)$ & \\
\hline Short methotrexate & $19(70.4 \%)$ & $6(100 \%)$ & $13(61.9 \%)$ & \\
\hline Use immunosuppressant at vaccination & $20(74.1 \%)$ & $6(100 \%)$ & $14(66.7 \%)$ & 0.1548 \\
\hline $\begin{array}{l}\text { Cessation of immunosuppressant shile } \\
\text { observation periods }\end{array}$ & $10(37 \%)$ & 0 & $10(47.6 \%)$ & 0.057 \\
\hline Anti-HBs at baseline, median & $113(3-1000<)$ & $47.7(3.6-273)$ & $172(3-1000<)$ & 0.0971 \\
\hline Anti-HBs at vaccination, median & $34.8(<2.5-1000<)$ & $11.7(<2.5-95.3)$ & $37(<2.5-1000<)$ & 0.1438 \\
\hline Anti-HBc at baseline, median & $17.9(1.8-124)$ & $13.3(1.8-46.9)$ & $17.9(2.5-124)$ & 0.3453 \\
\hline HB vaccine response, $n(\%)$ & $10(37 \%)$ & $3(50 \%)$ & $7(33.3 \%)$ & 0.6382 \\
\hline $\begin{array}{l}\text { Time to HBV reactivation } \\
\text { (months), median }\end{array}$ & - & $17.5(14-27)$ & - & \\
\hline $\begin{array}{l}\mathrm{HBV} \text {-DNA }(\log \mathrm{IU} / \mathrm{mL}) \text { at } \\
\text { reactivation, median }\end{array}$ & - & $1.65(1.4-4)$ & - & \\
\hline
\end{tabular}

were considered to have minimal protective-antibody titers (Fig. 4).

Patients with immunosuppression-associated HBV reactivation reportedly show a high degree of genetic complexity in the S-HBsAg sequences in their viral isolates, suggesting that $\mathrm{HBsAg}$ mutations may cause reactivation [18]. HB vaccination reportedly selects $\mathrm{HBsAg}$ escape mutations under immunosuppressed conditions; therefore, we performed $\mathrm{HBs}$ Ag sequencing after $\mathrm{HB}$ vaccination to examine the relationship between reactivation and escape mutations. Induction of $\mathrm{HBsAg}$ escape mutants after liver transplantation [24] and HSCT [25, 26] have been reported principally in two clinical settings: vaccinated newborns of $\mathrm{HBV}$-infected mothers and recipients of orthotopic liver transplant receiving human monoclonal anti-HBs or hyperimmune HBV immunoglobulins [27, 28]. Amino acid substitutions within the "a" determinant of HBsAg can lead to conformational alterations that affect binding of neutralizing antibodies. The most frequent substitutions include sG145A and sD144E, although many other substitutions have been described in the HBsAg outside of the "a" determinant sequence and in the pre-S region [29]. Here, only a single-HBsAg escape mutant (sD144E) was detected, with sL110I, sK122R, sD144E, and sR160K substitutions also present in the major hydrophobic region. Notably, no escape mutants were detected in patient 42 and patient 13 , who had serum anti-HBs titers $>10 \mathrm{mIU} / \mathrm{mL}$ (112 and $39.8 \mathrm{mIU} / \mathrm{mL}$, respectively). This suggests the importance of both cell-mediated and humoral immunity for controlling HBV. In fact, anti-HBs titers were $10 \mathrm{mIU} / \mathrm{mL}$ or less in four patients without $\mathrm{HBV}$ reactivation, and we consider that $\mathrm{T}$ cells were controlling HBV in these patients (Fig. 4). Nonetheless, vaccination is likely to select for escape mutations in the HBsAg gene during immunosuppressive 
Table 3 Characteristics of responders and non-responders to $\mathrm{HB}$ vaccination.

\begin{tabular}{|c|c|c|c|}
\hline & $\begin{array}{l}\text { HBV vaccine } \\
\text { responder } n=10\end{array}$ & $\begin{array}{l}\text { HBV vaccine non } \\
\text { responder } n=17\end{array}$ & $P$ \\
\hline Age, mean & $61(34-66)$ & $58(50-72)$ & 0.9115 \\
\hline Male, $n(\%)$ & $3(30 \%)$ & $12(70.6 \%)$ & 0.0568 \\
\hline \multicolumn{4}{|l|}{ Primary disease, $n(\%)$} \\
\hline AML & $1(10 \%)$ & $6(35.3 \%)$ & \\
\hline ALL & $3(30 \%)$ & $1(5.9 \%)$ & \\
\hline CML & $1(10 \%)$ & 0 & \\
\hline MDS & 0 & $6(35.3 \%)$ & \\
\hline MM & $2(20 \%)$ & $2(11.8 \%)$ & \\
\hline NHL & $3(30 \%)$ & $2(11.8 \%)$ & \\
\hline \multicolumn{4}{|l|}{ Stem cell source, $n(\%)$} \\
\hline Bone marrow & $4(40 \%)$ & $11(64.7 \%)$ & 0.2566 \\
\hline Autologous PBSC & $3(30 \%)$ & $2(11.8 \%)$ & \\
\hline Allogeneic PBSC & $3(30 \%)$ & $3(17.6 \%)$ & \\
\hline $\mathrm{CB}$ & 0 & $1(5.9 \%)$ & \\
\hline \multicolumn{4}{|l|}{ Conditioning therapy, $n(\%)$} \\
\hline MAC/RIC & $7(70 \%) / 3(30 \%)$ & $9(52.9 \%) / 8(47.1 \%)$ & 0.4475 \\
\hline HLA match, $n(\%)$ & $8(80 \%)$ & $9(52.9 \%)$ & 0.2305 \\
\hline Acute GVHD, $n(\%)$ & $4(40 \%)$ & $9(52.9 \%)$ & 0.6946 \\
\hline Chronic GVHD, $n(\%)$ & $6(60 \%)$ & $10(58.8 \%)$ & 0.9999 \\
\hline \multicolumn{4}{|l|}{ Immunosuppressant, $n(\%)$} \\
\hline Corticosteroid & $6(60 \%)$ & $12(70.6 \%)$ & 0.6831 \\
\hline Cyclosporine & $3(30 \%)$ & $2(11.8 \%)$ & 0.3261 \\
\hline Tacrolimus & $6(60 \%)$ & $12(70.6 \%)$ & 0.6831 \\
\hline Mycophenolate mofetil & $1(10 \%)$ & $2(11.8 \%)$ & 0.9999 \\
\hline Short methotrexate & $5(50 \%)$ & $14(82.4 \%)$ & 0.1019 \\
\hline Use immunosuppressant at vaccination & $6(60 \%)$ & $13(76.5 \%)$ & 0.4147 \\
\hline $\begin{array}{l}\text { Cessation of immunosuppressant while } \\
\text { observation periods }\end{array}$ & $4(40 \%)$ & $6(35.3 \%)$ & 0.9999 \\
\hline
\end{tabular}

treatment following HSCT; therefore, such cases warrant careful monitoring.

Recently, the response (anti-HBs titers of $>10 \mathrm{mIU} / \mathrm{mL}$ ) to $\mathrm{HB}$ vaccine in normal healthy volunteers was reported to be $90 \%$ [30]. Furthermore, $64 \%$ of post-HSCT patients seroconverted to anti-HBs-positive [31]. Considering these reports, it appears that our 37\% (10/27) response to vaccination is low. The anti-HBc-positive patients were past HBV-infected patients and would be expected to have a strong secondary immune response to vaccination [32]. Two possible reasons may explain the low response rate to vaccination. Firstly, at 12 months after HSCT, almost all recipients' $\mathrm{T}$ and $\mathrm{B}$ cells have been replaced with donorderived cells [33], suggesting presence of only few recipient-derived memory $\mathrm{T}$ and $\mathrm{B}$ cells. If donor is an HBV-resolved infection case (anti-HBc positive), it may contribute to anti-HBs production via memory $\mathrm{T}$ cells after HSCT [34-36]. Unfortunately, the donor for most patients with HBV reactivation was from a bone marrow bank, and it was not possible to analyze whether donor-derived HBV infection affected reactivation. Secondly, the host ability to produce antibody is reduced by immunosuppressive therapies. A recent report indicated HLA-DR-DQ and butyrophilin-like protein 2 to be important in response to $\mathrm{HB}$ vaccine [30], and future studies are necessary to better understand these host factors.

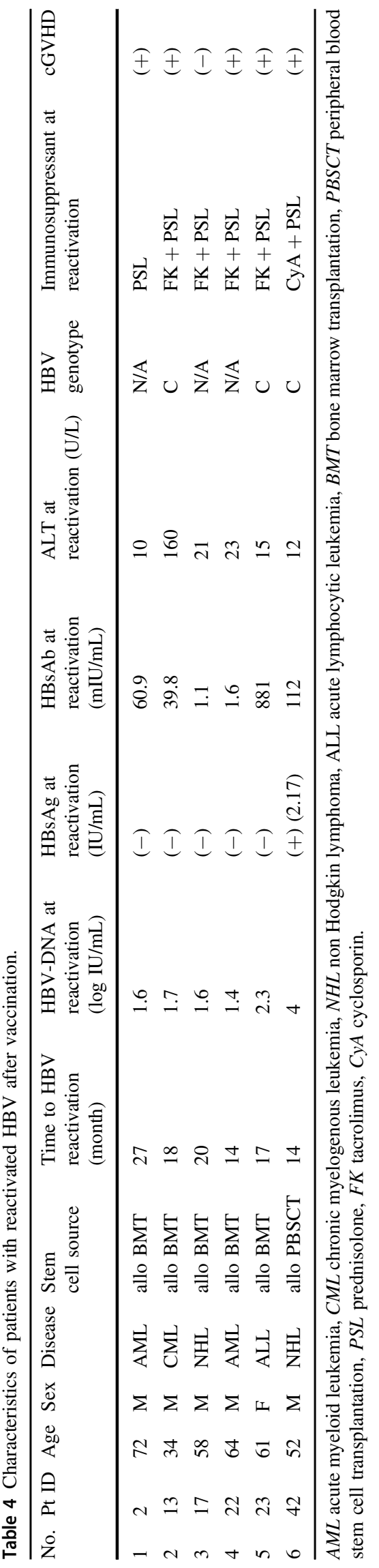


Fig. 3 Factors associated with $\mathrm{HBV}$ reactivation after vaccination. Factors associated with $\mathrm{HBV}$ reactivation after vaccination for (a) all HSCT patients with or without cessation of immunosuppressant,

(b) allogeneic HSCT patients with or without cessation of immunosuppressant, (c) all HSCT patients with anti-HBs titer $<10 \mathrm{mIU} / \mathrm{mL}$ or $>10 \mathrm{mIU} / \mathrm{mL}$ at baseline, and (d) allogeneic HSCT patients with anti-HBs titer $<10 \mathrm{mIU} / \mathrm{mL}$ or $>10 \mathrm{mIU} / \mathrm{mL}$ at baseline. Risk factors associated with HBV reactivation after vaccination were evaluated using the Fine and Gray model for univariate analysis. We defined censor for any reasons as competing risk. $P$ values $<0.05$ were considered to be statistically significant.
All HSCT

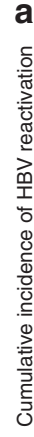

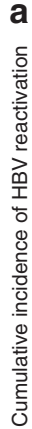

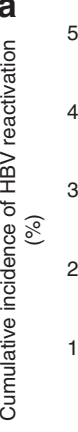

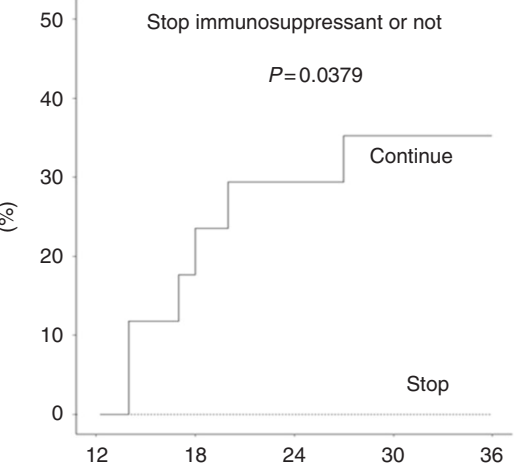

Period to HBV reactivation after HSCT (months)
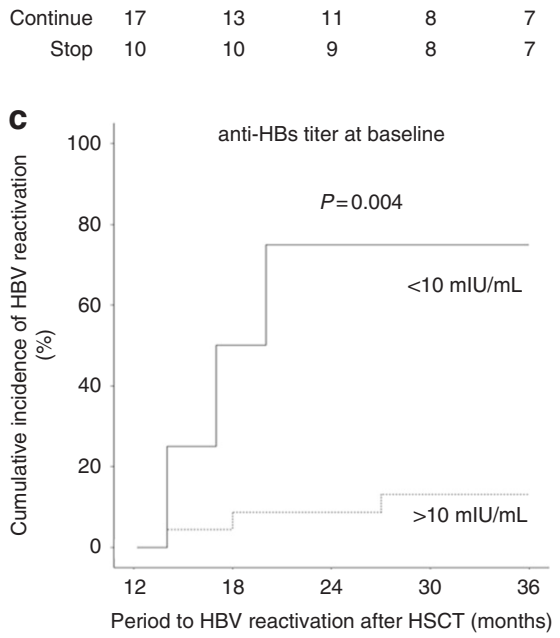

$>10 \mathrm{mIU} / \mathrm{mL}$

$<10 \mathrm{mlU} / \mathrm{mL} \quad 4$ b

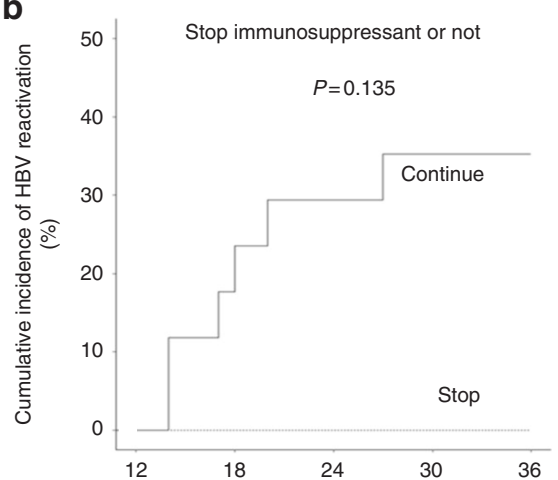

Period to HBV reactivation after HSCT (months)

$\begin{array}{rccccc}\text { Continue } & 17 & 13 & 11 & 8 & 7 \\ \text { Stop } & 5 & 5 & 4 & 4 & 4\end{array}$

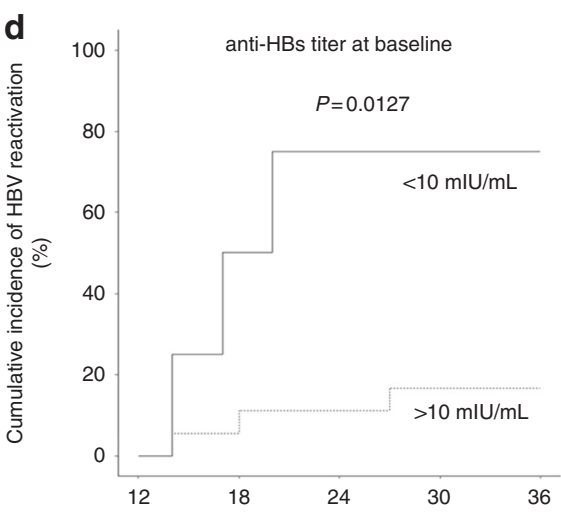

Period to HBV reactivation after HSCT (months)

$\begin{array}{cccccc}>10 \mathrm{mlU} / \mathrm{mL} & 18 & 16 & 14 & 12 & 10 \\ <10 \mathrm{mlU} / \mathrm{mL} & 4 & 3 & 2 & 2 & 1\end{array}$ a

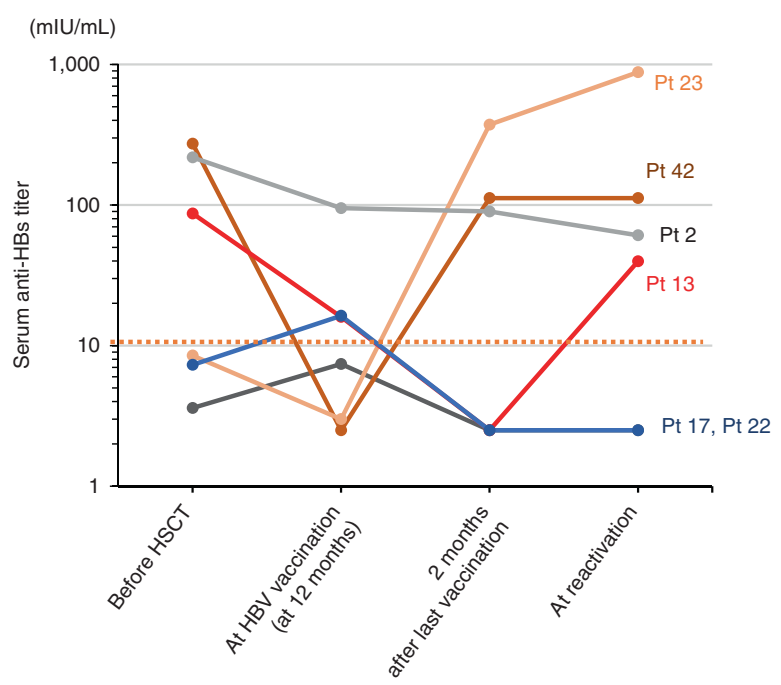

b
No HBV reactivation

$$
(\mathrm{mlU} / \mathrm{mL})
$$

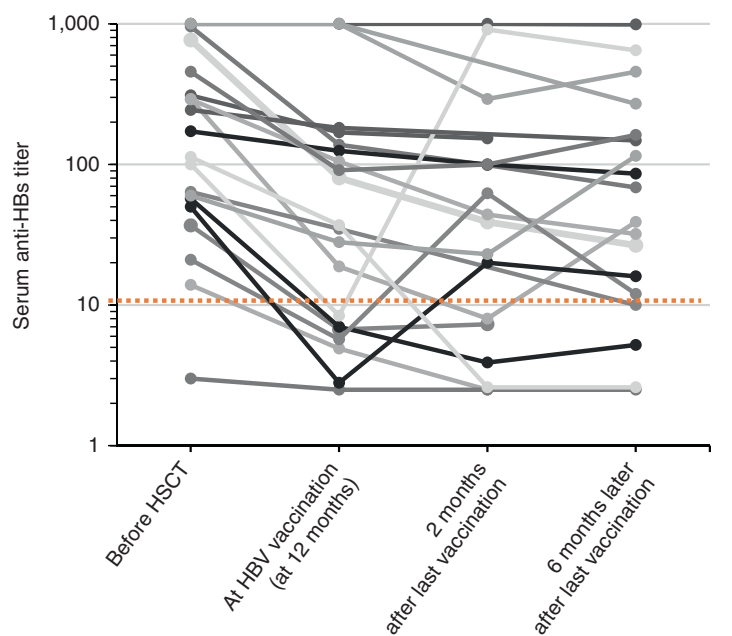

Fig. 4 Changes in serum anti-HBs titer after vaccination. Changes in serum anti-HBs are shown before HSCT, after the first vaccination, 2 or 6 months after final vaccination for (a) HBV-reactivated and (b) no reactivated patients. 


\section{a}

No 1

60

$\begin{array}{lllllllllllllllllllllllllllllllllllllllll}M & & & \end{array}$

13
23

42

61

S P T T S C P P P I C C P G 13

23

42

121

144

180

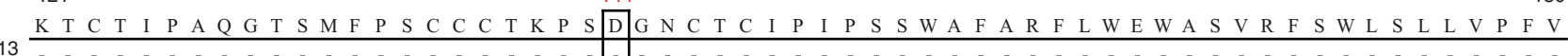

$23 \mathrm{R}$

42

181

226

Q W F V G L S P T V W L S V I W M M W Y W G P S L Y N I L S

13 23

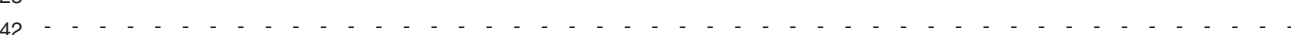

b

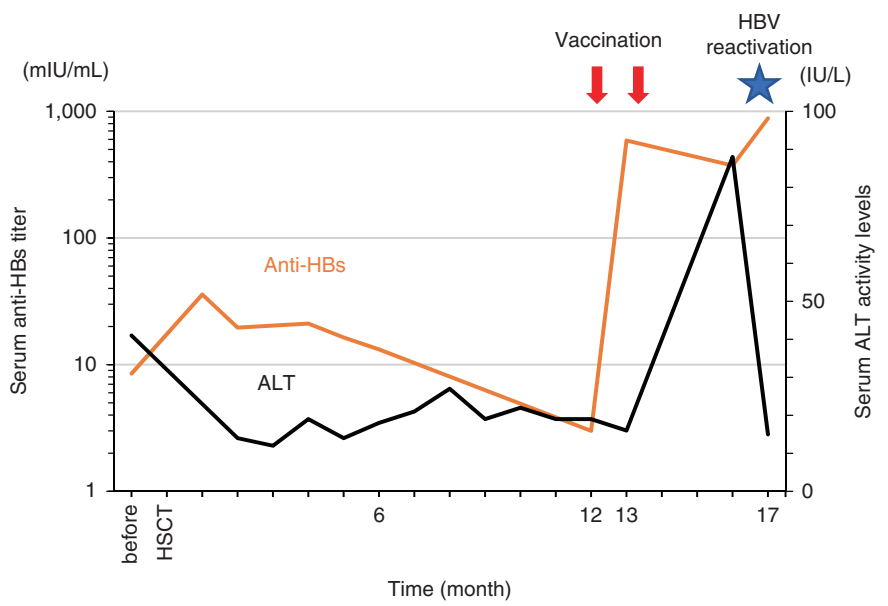

Fig. 5 Amino acid sequences of hepatitis $B$ surface antigen and clinical course of patient 23 (Pt 23). a Sequence alignments with consensus (top line) for three patients $(13,23$, and 42) who exhibited $\mathrm{HBV}$ reactivation after $\mathrm{HB}$ vaccination. Only residues that were different from the consensus sequence are shown. b Clinical course of

reactivated $\mathrm{HBV}$ infection for $\mathrm{Pt} 23$, with an $\mathrm{HBsAg}$ escape mutation after $\mathrm{HB}$ vaccination. Orange lines indicate serum anti-HBs titer levels, and black lines indicate serum alanine aminotransferase levels. Red arrows indicate vaccination time points.

Discontinuation of immunosuppressive treatment was associated with HBV reactivation after vaccination. Although immunosuppressants are usually used for prevention and treatment of chronic GVHD, they have reportedly been implicated in $\mathrm{HBV}$ reactivation [11]. Among the immunosuppressants, use of corticosteroids was nearly significantly $(P=0.056)$ associated with reactivation. Corticosteroids can act synergistically to promote viral replication through direct transcriptional regulation of the HBV genome [37]; thus, discontinuation of steroid treatment may be an important factor for preventing reactivation.

HBV reactivation-associated liver disease (de novo hepatitis) after allogeneic HSCT is often temporary and not serious, although fatal liver damage has been occasionally reported [38, 39]. In the 13 patients with HBV reactivation in this study, most showed no biochemical parameters of liver damage. In addition, no patient developed severe liver failure owing to antiviral treatment at onset of $\mathrm{HBV}$

reactivation. As previously reported $[11,40]$, in HSCT that causes frequent reactivation, periodic monitoring of $\mathrm{HBV}$ DNA facilitates timely therapeutic intervention to prevent serious liver damage. Furthermore, $15 \%$ patients with HBV reactivation were identified within 12 months after HSCT in this study. For these very early reactivation cases, it is important to prevent reactivation by NA prophylaxis. We propose that cases where the anti-HBs titer at the time of HSCT is low (10 mIU/mL or less) should be considered for prophylactic administration with a focus on treatment target.

Cost-effectiveness is a very important issue, and in the current study, medical expenses were calculated for Japan. The price of lamivudine drug is 484.7 yen/100 mg, amounting to 15000 yen a month if taken once a day. In contrast, HBV-DNA testing costs about 2800 yen per month. Since HBV-DNA testing costs are lower, we consider NA administration economical when reactivated by HBV-DNA monitoring every 1-3 months. However, as 
with the preventive administration of lamivudine, the question is how long it will be necessary to measure HBVDNA.

In conclusion, post-HSCT HBV reactivation was found to occur at a constant rate after vaccination. However, no reactivation was observed in patients in whom immunosuppressant administration was discontinued after vaccination. Our findings suggest that HBV reactivation depends on the host's immune function. As one of the three tested HBV-reactivated patients showed an HBsAg escape mutation following vaccination, vaccination could be a factor inducing HBsAg escape mutation. After HSCT for resolved $\mathrm{HBV}$-infected patients, preventive administration of antiviral drugs was tested; however, increasing the number of tested patients is necessary for greater statistical power and better assessing the efficacy, safety, and cost-effectiveness of the vaccination.

Acknowledgements The authors thank Ms Akemi Ikoma, Ms Maiko Nishihara, and Dr Makoto Saito, Tokyo Metropolitan Komagome Hospital, Clinical Research Support Center, for their help in data management, statistical analyses, and administrative support. We thank Editage for English-language editing.

Funding This work was supported by a grant from the Research Program on Hepatitis (18fk0210035h0001) from the Japan Agency for Medical Research and Development.

\section{Compliance with ethical standards}

Conflict of interest The authors declare that they have no conflict of interest.

Publisher's note Springer Nature remains neutral with regard to jurisdictional claims in published maps and institutional affiliations.

Open Access This article is licensed under a Creative Commons Attribution 4.0 International License, which permits use, sharing, adaptation, distribution and reproduction in any medium or format, as long as you give appropriate credit to the original author(s) and the source, provide a link to the Creative Commons license, and indicate if changes were made. The images or other third party material in this article are included in the article's Creative Commons license, unless indicated otherwise in a credit line to the material. If material is not included in the article's Creative Commons license and your intended use is not permitted by statutory regulation or exceeds the permitted use, you will need to obtain permission directly from the copyright holder. To view a copy of this license, visit http://creativecommons. org/licenses/by/4.0/.

\section{References}

1. Hoofnagle JH. Reactivation of hepatitis B. Hepatology. 2009;49 5 Suppl :S156-165. https://doi.org/10.1002/hep.22945.

2. Goyama S, Kanda Y, Nannya Y, Kawazu M, Takeshita M, Niino $\mathrm{M}$, et al. Reverse seroconversion of hepatitis B virus after hematopoietic stem cell transplantation. Leuk Lymphoma. 2002;43:2159-63. https://doi.org/10.1080/1042819021000033042.
3. Hammond SP, Borchelt AM, Ukomadu C, Ho VT, Baden LR, Marty FM. Hepatitis B virus reactivation following allogeneic hematopoietic stem cell transplantation. Biol Blood Marrow Transplant. 2009;15:1049-59. https://doi.org/10.1016/j.bbmt. 2009.05.001.

4. Kusumoto S, Tanaka Y, Ueda R, Mizokami M. Reactivation of hepatitis $\mathrm{B}$ virus following rituximab-plus-steroid combination chemotherapy. J Gastroenterol. 2011;46:9-16. https://doi.org/10. 1007/s00535-010-0331-4.

5. Vigano M, Vener C, Lampertico P, Annaloro C, Pichoud C, Zoulim F. et al. Risk of hepatitis B surface antigen seroreversion after allogeneic hematopoietic SCT. Bone Marrow Transpl. 2011;46:125-31. https://doi.org/10.1038/bmt.2010.70.

6. Dhedin N, Douvin C, Kuentz M, Saint Marc MF, Reman O, Rieux $\mathrm{C}$, et al. Reverse seroconversion of hepatitis B after allogeneic bone marrow transplantation: a retrospective study of 37 patients with pretransplant anti-HBs and anti-HBc. Transplantation. 1998;66:616-9.

7. Onozawa M, Hashino S, Izumiyama K, Kahata K, Chuma M, Mori A, et al. Progressive disappearance of anti-hepatitis B surface antigen antibody and reverse seroconversion after allogeneic hematopoietic stem cell transplantation in patients with previous hepatitis B virus infection. Transplantation. 2005;79:616-9.

8. Moses SE, Lim Z, Zuckerman MA. Hepatitis B virus infection: pathogenesis, reactivation and management in hematopoietic stem cell transplant recipients. Expert Rev Anti Infect Ther. 2011;9:891-9. https://doi.org/10.1586/eri.11.105.

9. European Association For The Study Of The L. EASL clinical practice guidelines: management of chronic hepatitis B virus infection. J Hepatol. 2012;57:167-85. https://doi.org/10.1016/j. jhep.2012.02.010.

10. Mallet V, van Bommel F, Doerig C, Pischke S, Hermine O, Locasciulli A, et al. Management of viral hepatitis in patients with haematological malignancy and in patients undergoing haemopoietic stem cell transplantation: recommendations of the 5th European Conference on Infections in Leukaemia (ECIL-5). Lancet Infect Dis. 2016;16:606-17. https://doi.org/10.1016/ S1473-3099(16)00118-3.

11. Seto WK, Chan TS, Hwang YY, Wong DK, Fung J, Liu KS, et al. Hepatitis B reactivation in occult viral carriers undergoing hematopoietic stem cell transplantation: a prospective study. Hepatology. 2017;65:1451-61. https://doi.org/10.1002/hep. 29022.

12. Aoki J, Kowazaki Y, Ohtsuki T, Okamoto R, Ohashi K, Hayashi $\mathrm{S}$, et al. Kinetics of peripheral hepatitis B virus-specific CD8(+) $\mathrm{T}$ cells in patients with onset of viral reactivation. J Gastroenterol. 2012. https://doi.org/10.1007/s00535-012-0676-y.

13. Knoll A, Boehm S, Hahn J, Holler E, Jilg W. Reactivation of resolved hepatitis B virus infection after allogeneic haematopoietic stem cell transplantation. Bone Marrow Transpl. 2004;33:925-9. https://doi.org/10.1038/sj.bmt.1704457.

14. Cordonnier C, Einarsdottir S, Cesaro S, Di Blasi R, Mikulska M, Rieger C, et al. Vaccination of haemopoietic stem cell transplant recipients: guidelines of the 2017 European Conference on Infections in Leukaemia (ECIL 7). Lancet Infect Dis. 2019;19: e200-e212. https://doi.org/10.1016/S1473-3099(18)30600-5.

15. Rubin LG, Levin MJ, Ljungman P, Davies EG, Avery R, Tomblyn M, et al. 2013 IDSA clinical practice guideline for vaccination of the immunocompromised host. Clin Infect Dis. 2014;58:e44-100. https://doi.org/10.1093/cid/cit684.

16. Sugauchi F, Mizokami M, Orito E, Ohno T, Kato H, Suzuki S, et al. A novel variant genotype $\mathrm{C}$ of hepatitis $\mathrm{B}$ virus identified in isolates from Australian Aborigines: complete genome sequence and phylogenetic relatedness. J Gen Virol. 2001;82:883-92. https://doi.org/10.1099/0022-1317-82-4-883. 
17. Sugiyama M, Inui A, Shin IT, Komatsu H, Mukaide M, Masaki N, et al. Easy-to-use phylogenetic analysis system for hepatitis B virus infection. Hepatol Res. 2011;41:936-45. https://doi.org/10. 1111/j.1872-034X.2011.00859.x.

18. Inuzuka $\mathrm{T}$, Ueda $\mathrm{Y}$, Arasawa $\mathrm{S}$, Takeda $\mathrm{H}$, Matsumoto $\mathrm{T}$, Osaki $\mathrm{Y}$, et al. Expansion of viral variants associated with immune escape and impaired virion secretion in patients with HBV reactivation after resolved infection. Sci Rep. 2018;8:18070 https:// doi.org/10.1038/s41598-018-36093-w.

19. Salpini R, Colagrossi L, Bellocchi MC, Surdo M, Becker C, Alteri C, et al. Hepatitis B surface antigen genetic elements critical for immune escape correlate with hepatitis B virus reactivation upon immunosuppression. Hepatology. 2015;61:823-33. https://doi. org/10.1002/hep.27604.

20. Onozawa M, Hashino S, Darmanin S, Okada K, Morita R, Takahata $\mathrm{M}$, et al. HB vaccination in the prevention of viral reactivation in allogeneic hematopoietic stem cell transplantation recipients with previous $\mathrm{HBV}$ infection. Biol Blood Marrow Transplant. 2008;14:1226-30. https://doi.org/10.1016/j.bbmt. 2008.08.007.

21. Ljungman P, Engelhard D, de la Camara R, Einsele H, Locasciulli A, Martino R, et al. Vaccination of stem cell transplant recipients: recommendations of the Infectious Diseases Working Party of the EBMT. Bone Marrow Transpl. 2005;35:737-46. https://doi.org/ 10.1038/sj.bmt. 1704870.

22. Takahata M, Hashino S, Onozawa M, Shigematsu A, Sugita J, Fujimoto K, et al. Hepatitis B virus (HBV) reverse seroconversion (RS) can be prevented even in non-responders to hepatitis B vaccine after allogeneic stem cell transplantation: long-term analysis of intervention in RS with vaccine for patients with previous HBV infection. Transpl Infect Dis. 2014;16:797-801. https://doi. org/10.1111/tid.12283.

23. Hwang JP, Lok AS. Management of patients with hepatitis B who require immunosuppressive therapy. Nat Rev Gastroenterol Hepatol. 2014;11:209-19. https://doi.org/10.1038/nrgastro.2013. 216.

24. Ishigami M, Kamei H, Nakamura T, Katano Y, Ando H, Kiuchi T, et al. Different effect of HBV vaccine after liver transplantation between chronic HBV carriers and non-HBV patients who received $\mathrm{HBcAb}$-positive grafts. J Gastroenterol. 2011;46:367-77. https://doi.org/10.1007/s00535-010-0313-6.

25. Romano L, Paladini S, Galli C, Raimondo G, Pollicino T, Zanetti AR. Hepatitis B vaccination. Hum Vaccin Immunother. 2015;11:53-57. https://doi.org/10.4161/hv.34306.

26. Waters JA, Kennedy M, Voet P, Hauser P, Petre J, Carman W, et al. Loss of the common "A" determinant of hepatitis B surface antigen by a vaccine-induced escape mutant. J Clin Investig. 1992;90:2543-7. https://doi.org/10.1172/JCI116148.

27. Carman WF, Van Deursen FJ, Mimms LT, Hardie D, Coppola R, Decker $\mathrm{R}$, et al. The prevalence of surface antigen variants of hepatitis B virus in Papua New Guinea, South Africa, and Sardinia. Hepatology. 1997;26:1658-66. https://doi.org/10.1002/hep. 510260640.

28. Ghany MG, Ayola B, Villamil FG, Gish RG, Rojter S, Vierling $\mathrm{JM}$, et al. Hepatitis B virus $\mathrm{S}$ mutants in liver transplant recipients who were reinfected despite hepatitis B immune globulin prophylaxis. Hepatology. 1998;27:213-22. https://doi.org/10.1002/ hep.510270133.

29. Weber B. Genetic variability of the $S$ gene of hepatitis B virus: clinical and diagnostic impact. J Clin Virol. 2005;32:102-12. https://doi.org/10.1016/j.jcv.2004.10.008.

30. Nishida N, Sugiyama M, Sawai H, Nishina S, Sakai A, Ohashi J, et al. Key HLA-DRB1-DQB1 haplotypes and role of the BTNL2 gene for response to a hepatitis B vaccine. Hepatology. 2018. https://doi.org/10.1002/hep.29876.

31. Jaffe D, Papadopoulos EB, Young JW, O'Reilly RJ, Prockop S, Kernan NA, et al. Immunogenicity of recombinant hepatitis B vaccine (rHBV) in recipients of unrelated or related allogeneic hematopoietic cell (HC) transplants. Blood. 2006;108:2470-5. https://doi.org/10.1182/blood-2006-04-006981.

32. Gessoni G, Beggio S, Barin P, Favarato M, Galli C, Valverde S, et al. Significance of anti-HBc only in blood donors: a serological and virological study after hepatitis B vaccination. Blood Transfus. 2014;12 Suppl 1 :s63-68. https://doi.org/10.2450/2013.0227-12.

33. Tomblyn M, Chiller T, Einsele H, Gress R, Sepkowitz K, Storek J, et al. Guidelines for preventing infectious complications among hematopoietic cell transplantation recipients: a global perspective. Biol Blood Marrow Transplant. 2009;15:1143-238. https://doi. org/10.1016/j.bbmt.2009.06.019.

34. Ilan Y, Nagler A, Adler R, Tur-Kaspa R, Slavin S, Shouval D. Ablation of persistent hepatitis B by bone marrow transplantation from a hepatitis B-immune donor. Gastroenterology. 1993;104: 1818-21. https://doi.org/10.1016/0016-5085(93)90664-x.

35. Ilan Y, Nagler A, Zeira E, Adler R, Slavin S, Shouval D. Maintenance of immune memory to the hepatitis $\mathrm{B}$ envelope protein following adoptive transfer of immunity in bone marrow transplant recipients. Bone Marrow Transpl. 2000;26:633-8. https:// doi.org/10.1038/sj.bmt.1702571.

36. Lau GK, Lok AS, Liang RH, Lai CL, Chiu EK, Lau YL, et al. Clearance of hepatitis B surface antigen after bone marrow transplantation: role of adoptive immunity transfer. Hepatology. 1997;25:1497-501. https://doi.org/10.1002/hep.510250631.

37. Tur-Kaspa R, Burk RD, Shaul Y, Shafritz DA. Hepatitis B virus DNA contains a glucocorticoid-responsive element. Proc Natl Acad Sci USA. 1986;83:1627-31.

38. Iwai K, Tashima M, Itoh M, Okazaki T, Yamamoto K, Ohno H, et al. Fulminant hepatitis B following bone marrow transplantation in an HBsAg-negative, HBsAb-positive recipient; reactivation of dormant virus during the immunosuppressive period. Bone Marrow Transpl. 2000;25:105-8. https://doi.org/10.1038/sj.bmt. 1702093.

39. Sakamaki H, Sato Y, Mori SI, Ohashi K, Tanikawa S, Akiyama $\mathrm{H}$, et al. Hepatitis B virus reactivation in a patient with chronic GVHD after allogeneic peripheral blood stem cell transplantation. Int J Hematol. 2001;74:342-6.

40. Kusumoto S, Tanaka Y, Suzuki R, Watanabe T, Nakata M, Takasaki H, et al. Monitoring of hepatitis B virus (HBV) DNA and risk of HBV reactivation in B-cell lymphoma: a Prospective Observational Study. Clin Infect Dis. 2015;61:719-29. https://doi. org/10.1093/cid/civ344. 